\title{
MENTAL WORKLOAD OF AIR TRAFFIC CONTROL (ATC) PERSONNEL AT ADISUTJIPTO INTERNATIONAL AIRPORT
}

\author{
Via Choirul Seftiyana \\ Teknik Dirgantara - Institut Teknologi Dirgantara Adisutjipto \\ viachoiruls6@gmail.com
}

\begin{abstract}
Air traffic controllers are under excessive stress because of their job. This has been linked to aspects of ATC work such as high job demands, time or responsibility pressure, or inadequate equipment. Types of work that require more vigilance, such as air traffic controllers at airports, are closely related to mental jobs that require high concentration. Because there is a negative impact on a company if it gives mental workload too high or too low for its employees, it is necessary to measure it to find out the right mental workload for its employees. This study aims to calculate the mental workload felt by ATC personnel in the APP unit. Measurement of mental workload in this study using the NASA-TLX (National Aeronautics and Space Administration Task Load Index). This method measures 6 (six) dimensions of workload size, namely Mental Demand, Physical Demand, Temporal Demand, Performance, Effort and Frustation Level
\end{abstract}

Keywords: ATC, mental workload, NASA-TLX

\section{Pendahuluan}

Penerbangan adalah satu kesatuan sistem yang terdiri atas pemanfaatan wilayah udara, pesawat udara, bandar udara, angkutan udara, navigasi penerbangan, keselamatan, dan keamanan, lingkungan hidup, serta fasilitas penunjang, dan fasilitas umum lainnya. Keselamatan diartikan kepada hal-hal yang mencakup keselamatan penerbangan yang selalu berhubungan dengan aspek keamanan penerbangan.Fungsi keselamatan penerbangan di bandar udara yang berkenaan dengan pelaksanaan kegiatan pelayanan lalu lintas udara perlu adanya upaya peningkatan kualitas pelayanan dari sisi navigasi udara salah satunya dengan melakukan peningkatan peralatan navigasi. ${ }^{[1][2]}$ Jenis Pelayanan Lalu Lintas Penerbangan terdiri dari pelayanan pemanduan lalu lintas penerbangan (air traffic control service), pelayanan informasi penerbangan (flight information service), dan pelayanan saran lalu lintas penerbangan (advisory service) dan pelayanan kesiagaan (alerting service) (Peraturan Menteri Perhubungan Republik Indonesia Nomor PM 65 Tahun 2017 tentang Peraturan Keselamatan Penerbangan Sipil Bagian 170 Bab 1 Point 1.5 Halaman 13).

Berdasarkan Peraturan Menteri Perhubungan Republik Indonesia Nomor PM 65 Tahun 2017 tentang Peraturan Keselamatan Penerbangan Sipil Bagian 170 Bab 1 Point 1.4 Halaman 13 menjelaskan bahwa pelayanan lalu lintas penerbangan memiliki tujuan antara lain adalah untuk mencegah terjadinya tabrakan antar pesawat di udara, mencegah terjadinya tabrakan antar pesawat udara atau pesawat udara dengan halangan (obstruction) di manoeuvring area, memperlancar dan menjaga keteraturan arus lalu lintas penerbangan, memberikan petunjuk dan informasi yang berguna untuk keselamatan dan efisiensi penerbangan dan memberikan notifikasi (informasi) kepada organisasi terakait untuk bantuan pencarian dan pertolongan (search and rescue) dan membantu organisasi tersebut bila diperlukan. ${ }^{[3][5]}$

Di Indonesia para controller atau petugas pemandu lalu lintas udara bekerja di bawah Perusahaan Umum (Perum) Lembaga Penyelenggara Pelayanan Navigasi Indonesia (LPPNPI) atau lebih dkenal dengan AirNav Indonesia. Berdasarkan PP No. 77 tahun 2012 maksud dan tujuan pendirian Perum LPPNPI ialah melaksanakan penyediaan jasa pelayanan navigasi penerbangan sesuai dengan standar yang berlaku untuk mencapai efisiensi dan efektivitas 
penerbangan dalam lingkup nasional dan internasional. Sebagai Badan Usaha, tolak ukur kinerja AirNav Indonesia dilihat dari sisi keselamatan yang terdiri atas banyak unsur seperti Sumber Daya Manusia (SDM), peralatan, prosedur dan lain sebagainya yang semuanya harus mengikuti perkembangan dan standar yang diatur secara ketat dalam Civil Aviation Safety Regulations (CASR). Untuk memastikan bahwa keselamatan dalam penyediaan Air Traffic Services (ATS) dipertahankan, penyedia jasa pelayanan navigasi penerbangan harus menerapkan Sistem Manajemen Keselamatan (SMS) ATS untuk layanan navigasi penerbangan.

Sistem Manajemen Keselamatan (SMS) bertujuan untuk memastikan tingkat keselamatan sebagaimana yang telah ditetapkan oleh regulator dapat tercapai. Reviu keselamatan unit ATS harus dilakukan dengan teratur dan sistematis oleh personel yang memenuhi syarat pelatihan, pengamatan dan keahlian. ${ }^{[6][7]}$ Salah satu reviu keselamatan unit ATS untuk masalah regulasi harus memastikan bahwa volume traffic dan beban kerja controller tidak melebihi batas yang ditentukan dan reviu keselamatan untuk masalah operasional dan teknis harus memastikan bahwa :

a. Kondisi lingkungan kerja memenuhi tingkat suhu, kelembapan, sirkulasi udara, dan pencahayaan sesuai yang di persyaratkan, serta tidak mempengaruhi kerja controller

b. Sistem otomasi flight plan, dan data koordinasi, dan data pemanduan secara tepat waktu, akurat, dan mudah dikenali serta sesuai dengan prinsip-prinsip dalam Human Factors

c. Peralatan, termasuk perangkat input.output untuk sistem otomasi, dirancang dan diposisikan di posisi kerja dengan prinsip-prinsip ergonomi

d. Peralatan Communication, Navigation, Surveillence (CNS) berada dalam pemeliharaan yang baik

e. Catatan rinci atas kemampuan layanan dari sistem dan peralatan, disimpan dan ditinjau berkala.

Dari uraian diatas dijelaskan bahwa salah satu tujuan diterapkannya Sistem Manajemen Keselamatan (SMS) Air Traffic Services (ATS) untuk layanan navigasi penerbangan adalah untuk menghindari terjadinya beban kerja pada controller. beban kerja sendiri adalah "Jumlah kegiatan yang harus diselesaikan oleh seseorang ataupun sekelompok orang selama periode waktu tertentu dalam keadaan normal." Haryono (2004) dikutip dari psychology (2016). Beban kerja meliputi beban kerja fisik dan beban kerja mental, Jenis pekerjaan yang lebih memerlukan kesiapsiagaan tinggi (vigilance) seperti air traffic controller di bandar udara adalah sangat berhubungan dengan pekerjaan mental yang memerlukan konsentrasi tinggi.

Penelitian yang berjudul tentang kebutuhan personel Air Traffic Controller (ATC) di pusat pengendalian lalu lintas penerbangan Makassar. Berdasarkan penelitiannya diketahui bahwa para petugas pemandu lalu lintas udara (ATC) di Bandara Internasional Sultan Hasanudin Makassar mengalami tingkat kelelahan yang cukup signifikan. Hal ini tampak pada faktor fisik dan faktor psikologis. Pelaksanaan jam kerja petugas Air Traffic Controller (ATC) Pusat Pengendalian Lalu Lintas Penerbangan Makassar belum sepenuhnya memenuhi pedoman penetapan jam kerja yang telah diatur, meliputi batas jam kerja dalam sehari, jam istirahat ketika bekerja, batas maksimal jam kerja dalam sehari.

Penurunan jumlah SDM yang ideal juga menjadi permasalahan yang harus diselesaikan, karena pelaksanaan jam kerja di lapangan tidak dapat dilakukan dengan maksimal sesuai dengan pedoman penetapan jam kerja apabila jumlah SDM personel ATC terbatas. Suatu penelitian beban kerja operator Air Traffic Controller Bandara dengan menggunakan metode NASA-TLX. Berdasarkan hasil penelitian diketahui bahwa beban kerja mental operator APP dan ACC termasuk dalam skala tinggi yang dapat dilihat dari banyaknya operator yang berada pada kategori overload.

Pekerjaan ATC membutuhkan aktivitas mental (dimensi Mental Demand) yang tinggi seperti berpikir, memutuskan, menghitung, mengingat, dan melihat atau memantau dalam 
melakukan pekerjaannya. Solusi untuk mengurangi tingkat beban kerja mental yang tinggi dengan memperanggih sistem peralatan radar, pengaturan shift kerja, dan perbaikan individual operator ATC ketika bekerja. Dalam penelitian tentang pengaruh shift kerja terhadap beban kerja mental pada operator Air Traffic Control (ATC) berdasarkan hasil penelitian diketahui bahwa beban kerja mental operator ATC pada shift pagi termasuk ke dalam kategori beban kerja mental tinggi sekali dengan rata-rata skor 81 , shift siang termasuk ke dalam kategori beban kerja mental tinggi dengan rata-rata skor 77, dan shift malam termasuk ke dalam kategori beban kerja mental tinggi dengan rata-rata skor 77.

Shift kerja memiliki pengaruh terhadap beban kerja mental operator ATC. Rekomendasi perbaikan yang dapat diberikan terhadap operator ATC untuk meminimalisir beban kerja mental yang tinggi tersebut adalah pembagian wilayah pada Balikpapan TMA, penambahan SDM, serta penyediaan tempat istirahat yang memadai dan fasilitas di dalamnya. Aktivitas manusia dapat dibedakan dari pekerjaan yang didominasi dari aktivitas fisik dan pekerjaan yang di dominasi dari aktivitas mental, aktivitas fisik dan mental tersebut menimbulkan dampak, yaitu munculnya beban kerja. Jika seorang pekerja mempunyai kemampuan yang lebih tinggi dari tuntutan pekerjaannya maka akan timbul rasa bosan, sebaliknya apabila seorang pekerja mempunyai kemapuan lebih rendah dari tuntutan pekerjaannya, maka akan timbul kelelahan yang berlebih. Akibat lain dari beban kerja mental yang berlebihan akan berdampak adanya stres kerja.

Definisi dari beban kerja mental beban kerja merupakan selisih antara tuntutan beban kerja dari suatu tugas dengan kapasitas maksimum beban mental seseorang dalam kondisi termotivasi. Beban kerja mental seseorang dipengaruhi oleh:

a. Jenis aktivitas dan situasi kerjanya

b. Waktu respon dan waktu penyelesaian yang tersedia

c. Faktor individu seperti tingkat motivasi, keahlian, kelelahan, kejenuhan

d. Toleransi performasi yang dibutuhkan

Petugas Pemandu Lalu Lintas Udara (ATC) adalah petugas yang mengatur pergerakan pesawat yang terbang atau yang berada di daerah pergerakan di bandara seperti apron (tempat parkir pesawat) dan taxiway (tempat peralihan dari runway ke apron atau sebaliknya). ATC bekerja sesuai dengan tugas pokok pelayanan lalu lintas udara berdasarkan Peraturan Menteri Perhubungan Republik Indonesia Nomor PM 65 Tahun 2017 tentang Peraturan Keselamatan Penerbangan Sipil Bagian 170 Bab 1 Point 1.4 Halaman 13 menjelaskan lebih rinci bahwa pelayanan lalu lintas penerbangan memiliki tujuan antara lain adalah untuk :

a. mencegah terjadinya tabrakan antar pesawat di udara

b. Mencegah terjadinya tabrakan antar pesawat udara atau pesawat udara dengan halangan (obstruction) di manoeuvring area,

c. Memperlancar dan menjaga keteraturan arus lalu lintas penerbangan

d. Memberikan petunjuk dan informasi yang berguna untuk keselamatan dan efisiensi penerbangan dan memberikan notifikasi (informasi) kepada organisasi terakait untuk bantuan pencarian dan pertolongan (search and rescue) dan membantu organisasi tersebut bila diperlukan .

Dalam pelaksanaan tugasnya, sebagaimana yang dimaksud dalam PM No 65 tahun 2017 tentang peraturan keselamatan penerbangan sipil (PKPS) bagian 170 Bab 1 Point 1.5 Halaman 13, Pelayanan Pemanduan Lalu Lintas penerbangan (Air Traffic Control Services) pada ruang udara terkontrol terbagi menjadi 3 (tiga) bagian yaitu:

a. Area Control Service

Area control service yaitu pelayanan pemanduan lalu lintas penerbangan yang diberikan kepada controlled flight di Area penerbangan jelajah. 


\section{b. Approach Control Service}

Approach Control Service yaitu pelayanan pemanduan lalu lintas penerbangan yang diberikan kepada controlled flight untuk pesawat udara yang datang (arriving aircraft) dan pesawat udara yang berangkat (departing aircraft).

c. Aerodrome Control Service

Aerodrome Control Service yaitu pelayanan pemanduan lalu lintas penerbangan yang diberikan kepada aerodrome control traffic.

Pelayanan lalu lintas penerbangan sebagaimana yang dimaksud dalam PM No 65 tahun 2017 tentang peraturan keselamatan penerbangan sipil (PKPS) bagian $170 \mathrm{Bab} 1$ Point $1.5 \mathrm{Hal}$ 14 ditetapkan dengan mempertimbangkan paling sedikit:

a. Jenis lalu lintas penerbangan

b. Kepadatan arus lalu lintas penerbangan

c. Kondisi meteorologi

d. Kondisi sistem teknologi dan topografi

e. Fasilitas dan kelengkapan navigasi penerbangan dipesawat udara

Untuk memberikan Pelayanan lalu lintas penerbangan (air traffic services) sebagaimana yang dimaksud dalam PM No 65 tahun 2017 tentang Peraturan Keselamatan Penerbangan Sipil (PKPS) bagian 170 Bab 1 Point 1.9 Hal 19. Dibentuk unit pelayanan lalu lintas penerbangan (air traffic services) di aerodrome yang terdiri dari:

a. Unit pelayanan lalu lintas penerbangan di aerodrome yang terdiri

- Aerodrome Control Tower (TWR)

- Aerodrome Flight Information Services (AFIS)

- Aeronautical Station

b. Unit pelayanan lalu lintas penerbangan pada fase jelajah sampai fase pendekatan yang terdiri dari

$>$ Approach Control Unit (APP)

$>$ Terminal Control Area

c. Unit pelayanan navigasi penerbangan jelajah

$>$ Unit pelayanan navigasi penerbangan jelajah dengan pemanduanlalu lintas penerbangan (Area Control Centre/ACC)

$>$ Unit pelayanan navigasi penerbangan jelajah dengan pemanduan komunikasi penerbangan (Flight Information Centre/FIC dan Flight Service Station (FSS).

Ruang udara Yogyakarta termasuk dalam klasifikasi Kelas C, dimana ruang udara penerbangan yang diijinkan adalah penerbangan Instrument Flight Rules (IFR) dan Visual Flight Rules (VFR).

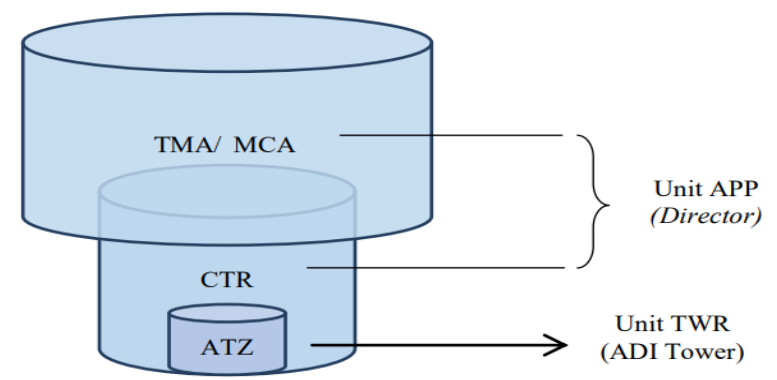

Gambar 1. Pembagian Ruang Udara Yogyakarta dan Unit yang Menangani 


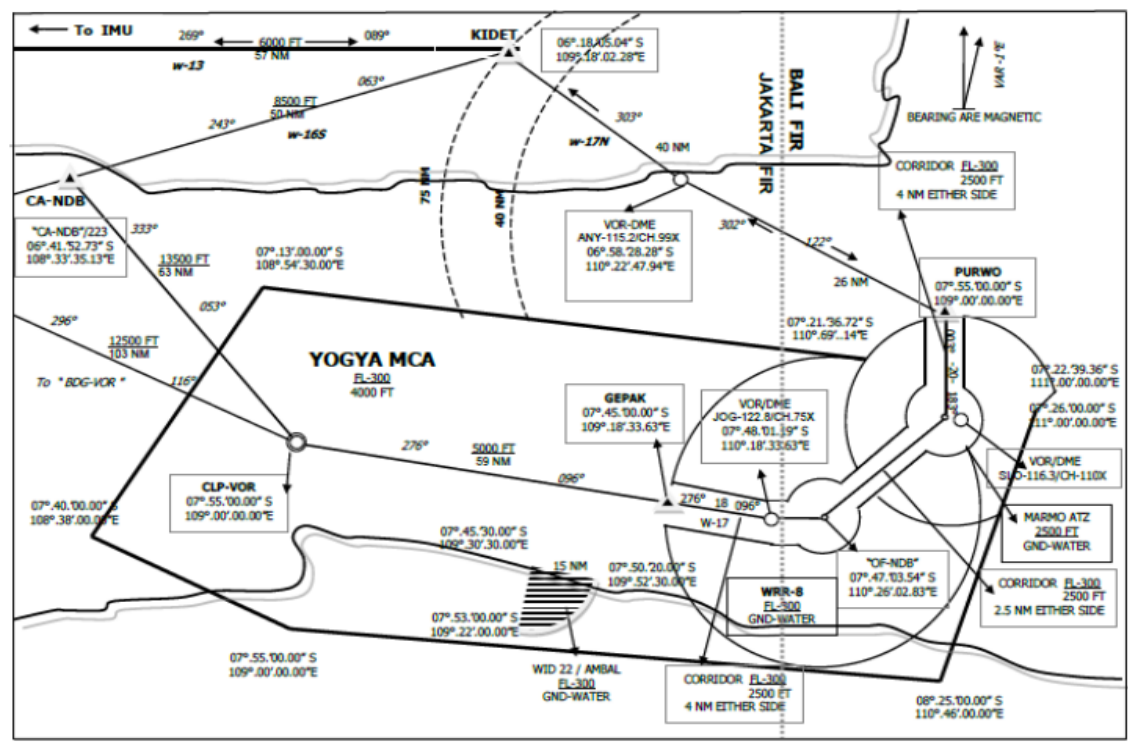

Gambar 2. Ruang Udara Yogyakarta

Ruang udara Yogyakarta terbagi menjadi 2 sektor, yaitu Control Area (CTR) dan Terminal Control Area (TMA). Di dalam CTR terdapat Aerodrome Traffic Zone (ATZ) sedangkan di dalam TMA terdapat ruang udara militer/ Military Control Area (MCA). Pesawat yang berada di ATZ dikendalikan oleh Unit TWR dan pesawat yang terbang di MCA dikendalikan oleh Unit APP. Lalu lintas penerbangan yang berada di dalam MCA tentu bukan hanya pesawat yang akan mendarat di Bandar Udara Adisutjipto namun terdapat pesawar yang terbang melintas (overflyimg). Ketika operasional penerbangan dipindahkan ke bandar udara Yogyakarta International Airport, maka tidak akan merubah tanggung jawab dan beban kerja ATC di Unit APP, hal itu dikarenakan batas vertical Unit APP sampai ketinggian 30.000 kaki dan batas lateral sejauh 20 NM berpusat pada "SO" NDB. Dikarenakan operasional ATC yang bekerja di Unit TWR dipindahkan ke bandar udara Yogyakarta International Airport, maka tanggung jawab petugas ATC di TWR Adisutjipto hanya mengendalikan pesawat militer dan pesawat komersil bertipe baling-baling (propeller).Unit APP yang ada di AirNav Indonesia cabanga Bandar Udara Internasional Adisutjipto terbagi menjadi 2 (dua) bagian yaitu:

1. APP Director : Untuk melayani pemanduan di dalam wilayah Yogyakarta CTR

2. APP Radar : Untuk melayani pemanduan di luar wilayah tersebut, berdasarkan sumber dari AIP Indonesia (Vol 1) untuk wilayah APP Radar Yogyakarta dilihat dari MSSR Coordinate yaitu 074707.0S 1102633.0E dengan Coverage 200 NM.

Pemegang lisensi dan rating personel pemandu lalu lintas penerbangan dalam menjalakan pemanduan lalu lintas penerbangan sesuai kewenangan yang dimilikinya harus memenuhi kententuan jumlah jam kerja sebagaimana yang disebutkan dalam peraturan Direktur Jenderal Perhubungan Udara Nomor KP 166 Tahun 2020 tentang penetapan standar teknis dan operasi bagian 69-01 (Manual of Standard Part 69-01) Lisensi, Rating, Pelatihan dan Kecakapan personel pemandu lalu lintas penerbangan. Jumlah jam kerja personel Air Traffic Control (ATC) diatur dalam peraturan Direktur Jenderal Perhubungan Udara Nomor KP 166 Tahun 2020 tentang pedoman teknis operasional bagian 69-01 (Advisory Circular part 69-01) disebutkan sebagai berikut:

a) Jumlah jam pemanduan dalam 1 (satu) minggu tidak melebihi batas maksimal dari 24 (dua puluh empat) jam.

b) Jumlah jam pemanduan dalam 1 (satu) hari tidak lebih dari 6 (enam) jam, dengan ketentuan pemanduan paling lama 2 (dua) jam berturut-turut, dan harus diberikan jeda waktu istirahat selama 1 (satu) jam, sehingga keseluruham jumlah jam kerja sebagai berikut : 
$>$ Jumlah jam kerja dalam 1 (satu) hari tidak lebih dari 8 (delapan) jam

$>$ Jumlah jam kerja dalam 1 (satu) minggu tidak lebih dari 40 jam

Jumlah jam kerja untuk Asistant Controller sebagai berikut :

a) Jumlah jam asistant pemanduan dalam 1 (satu) minggu tidak lebih dari 24 (dua puluh empat) jam.

b) Jumlah jam asistant pemanduan dalam 1 (satu) hari tidak lebih dari 6 (enam) jam, dengan ketentuan asistant pemanduan paling lama selama 3 (tiga) jam dan harus diberikan jeda waktu istirahat selama 1 (satu) jam, sehingga secara keseluruhan pengaturan jam kerja sebagai berikut :

$>$ Jumlah jam kerja dalam satu hari tidak lebih dari 8 (delapan) jam

$>$ Jumlah jam kerja dalam 1 (satu) minggu tidak lebih dari 40jam

Menurut ICAO Circular 241, Human Factors Digest No.8, Human Factors in Air Traffic Control, tentang "Basic Human Factors Issues in Air Traffic Control, Including Workstation Design and Personnel Selection and Training", yaitu Stress is workload of controllers are at the very high end of the stress spectrum due to the demanding nature of the job. Menjelaskan bahwa Stres adalah beban kerja pengontrol yang berada di ujung paling tinggi dari spektrum stres karena sifat pekerjaan yang menuntut.

Terdapat banyak sumber-sumber yang mempengaruhi stres pada para controller, antara lain:

a) Tuntutan pekerjaan seperti jumlah dari pesawat yang sedang dikontrol, periode puncak kepadatan lalu lintas udara, pesawat asing yang tidak berjadwal, terjadi peristiwa yang tdak terduga.

b) Prosedur Operasional, seperti tuntutan waktu, pelanggaran dari aturan, perasaan hilang control, takut terhadap konsekuensi kesalahan.

c) Jumlah waktu kerja, seperti terbatasnya kehandalan peralatan, kualitas dari peralatan komunikasi, jalur telepon, dan tata letak peralatan.

d) Lingkungan kerja, seperti pencahayaan ruangan, pantulan optic, tingkat kebisingan suara di ruangan, postur tubuh yang tidak nyaman, jumlah waktu istirahat, fasilitas dari relaksasi dan kantin, lift atau tangga/

e) Organisasi kerja, seperti hubungan kerja antar pekerja, kurangnya kontrol atau proses kerja , gaji dan imbalan.

Definisi dari Performed Based Navigation (PBN) "Area navigation based on performance requirements for aircraft operating along an ATS route, on an instrument approach procedure or in a designated airspace", yang berarti area navigasi berdasarkan persyaratan kinerja untuk pesawat yang beroperasi di sepanjang rute ATS, pada prosedur pendekatan instrumen, atau di wilayah udara yang ditentukan. (ICAO Doc 9613)

PBN terdiri dari tiga komponen:

a) Infrastruktur Navaid

Infrastruktur Navaid mengacu pada Navaid berbasis darat atau satelit. Navaid berbasis darat termasuk DME dan VOR. Navaid berbasis ruang angkasa mencakup GNSS.

b) Spesifikasi Navigasi

Spesifikasi Navigasi Seperangkat persyaratan pesawat dan awak udara yang diperlukan untuk mendukung operasi Navigasi berbasis Kinerja dalam wilayah udara yang ditentukan. RNAV adalah singkatan dari Area Navigation merupakan spesifikasi navigasi berdasarkan navigasi area yang tidak mencakup persyaratan untuk Performance Monitoring and Alerting Sytem atau pemantauan kinerja dan sistem peringatan. RNAV mempunyai kemampuan untuk menerbangkan pesawat dengan jalur penerbangan yang diinginkan, ditentukan oleh waypoints dan tidak harus oleh navaids bumi. Kemampuan RNAV terhubung dengan peralatan di dalam pesawat (sistem RNAV). Dibandingkan dengan prosedur konvensional yang dapat diterapkan 
pada aplikasi non-RNAV ketika pesawat melakukan navigasi berdasarkan sinyal langsung dari radio navaid berbasis darat. Kerugian dari jenis navigasi ini adalah bahwa rutenya tergantung pada lokasi beacon navigasi. Hal ini sering kali menghasilkan rute yang lebih panjang, sedangkan RNAV memungkinkan untuk definisi rute yang lebih langsung

\section{Metode Penelitian}

Jenis pembahasan dan analisis menggunakan metode kuantitatif. Penelitian kuantitatif adalah suatu proses menemukan pengetahuan yang menggunakan data berupa angka sebagai alat yang digunakan untuk menganalisis keterangan mengenai apa saja yang ingin diketahui. Metode kuantitatif yang digunakan dalam penelitian ini dengan bentuk kuesioner NASA-TLX, serta beberapa penjelasan secara deskriptif, ditutup oleh pemaparan berdasarkan kompilasi data primer dan sekunder yang telah diolah, dimana akhirnya dapat menghasilkan suatu kesimpulam sesuai tujuan penelitian. Penelitian dimulai dengan penyebaran kuesioner kepada petugas ATC. Kuesioner ini dibagikan berdasarkan pada saat jadwal shift kerja yang mereka jalani. Kuesioner ini menggunakan keusioner dari NASA Task Load Index (NASA-TLX).Setelah didapat data dari pengisian kuesioner tersebut maka selanjutnya akan dilakukan pengolahan data sesuai dengan rumusan yang terdapat pada NASA-TLX.Dalam Instrumen penelitian menggunakan tes yang mempunyai karekatristik untuk mengukur informan dengan sejumlah pertanyaan dan pernyataan dalam penelitian, biasanya dibuat garis besar tujuan dari penelitian dilakukan, Sukmadinata (2010). Penelitian dilaksanakan dengan mengumpulkan data yang dibutuhkan. Pengumpulan data haruslah didukung dengan menggunakan alat-alat penunjang yang tepat agar dalam pengolahannya data tersebut dapat dikatakan valid. Instrumen yang digunakan dalam penelitian ini antara lain:

$>$ Kuesioner NASA-TLX

Kuesioner NASA-TLX adalah berupa kuesioner dari NASA Task Load Index (NASATLX). NASA-TLX dipilih karena mencerminkan judul penelitian. Selain itu bertujuan untuk mengetahui beban kerja mental yang dirasakan oleh para responden yang akan diteliti. Instrumen NASA-TLX yang digunakan dalam penelitian ini terdiri dari enam domain yaitu Kebutuhan mental (KM), Kebutuhan Fisik (KF), Kebutuhan Waktu (KW), Performance (P), Tingkat Frustasi (TF), Tingkat Usaha (TU).

$>$ Software Statistika

Software Statistika digunakan untuk menguji normalitas data serta tingkat beban kerja petugas ATC yang bertujuan untuk memberikan kekuatan terhadap hasil penelitian agar penelitian tetap berada pada koridor ilmiah. Software Statistika yang digunakan dalam tugas akhir ini adalah SPSS for windows Version 22.0.

KP 166 tahun 2020 tentang penetapan standar teknis dan operasi

Rumusan yang digunakan untuk analisis menghitung kebutuhan personel AIR Traffic Controller (ATC) yaitu ;

Jumlah kebutuhan personel operasional Per Sektor

$$
=\frac{\text { Operating Hours X } 365 \text { X Set Crew dalam Sektor }}{\text { Jam Efektif Kerja Personel Setahun }}
$$

Dimana;

$365=$ jumlah hari dalam 1 tahun

$47=$ jumlah minggu dalam 1 tahun - waktu training, cuti dan sakit

$24=$ jumlah jam kerja minimal dalam 1 minggu

Data yang akan digunakan dalam penelitian ini terdiri dari dua yaitu data primer dan data sekunder, data primer berupa data yang didapat dari hasil pengisian kuesioner yang diperoleh dan pengolahan data primer dengan menggunakan program SPSS (Statistical Package for Social Science) for Windows Release versi 22. Sementara untuk data sekunder diperoleh 
melalui data-data dari pihak internal serta website jurnal-jurnal penelitian. Selanjutnya terkait dengan perangkat yang digunkaan untuk mengukur dan menganalisa beban kerja mental, maka peneliti menggunakan kuesioner dari NASA-TLX. Kuesioner tersebut dipilih karena merupakan metode yang sederhana dan sangat cocok digunakan dalam industri penerbangan seperti tugas ATC yang mengatur pergerakan lalu lintas dan navigasi Bandar udara Kuesioner ini mempunyai keunggulan yaitu lebih sensitif terhadap berbagai kondisi pekerjaan, setiap faktor dari penilaian dapat memberikan tambahan informasi mengenai struktur tugas, serta dalam proses penentuan keputusan lebih sederhana dan cepatUji normalitas data dilakukan untuk mengetahui data yang akan dianlisis terdistribusi secara normal atau tidak. Hasil dari uji normalitas data ini nantinya sangat berpengaruh terhadap pengujian statistic berikutnya. Uji normalitas yang digunakan dalam penelitian ini adalah uji normalitas Shapiro Wilk dengan bantuan SPSS 22.0. Uji One Sample T Test adalah pengujian yang digunakan untuk melihat rata-rata sampel yang diteliti dengan rata-rata populasi yang sudah ada. Syaratnya yang pertama melakukan Uji Normalitas yang digunakan untuk melihat sebaran data penelitian terdistribusi normal atau tidak, apabila data tidak terdistribusi normal maka dilakukan uji t (non parametrik) yaitu menggunakan uji proposi. Hasil dari uji one Sample T Test ditentukan dari nilai signifikannya. Nilai ini yang menentukan keputusan yang diambil dalam penelitian.

Nilai signifikansi (2-tailed) $<0.05$ menunjukkan adanya perbedaan yang signifikan antara variabel awal dengan variabel akhir. Ini menunjukkan terdapat pengaruh yang bermakna terhadap perbedaan perlakuan yang diberikan pada masing-masing variabel.

$>$ Nilai signifikansi (2-tailed) $>0.05$ menunjukkan tidak terdapat perbedaan yang signifikan antara variabel awal dengan variabel akhir. Ini menunjukkan tidak terdapat pengaruh yang bermakna terhadap perbedaan perlakukan yang diberikan pada masing-masing variabel

\section{Hasil Dan Pembahasan}

Data yang dihasilkan dari pengukuran beban kerja mental diukur menggunakan enam indikator yang ada pada NASA-TLX untuk mengetahui seberapa besar beban kerja mental yang dialami oleh personel. Enam indikator tersebut adalah Kebutuhan Mental (KM), Kebutuhan Fisik (KF), Kebutuhan Waktu (KW), Performance (P), Tingkat Frustasi (TF), Tingkat Usaha (TU). Pada tahap pembobotan terdiri dari 15 perbandingan berpasangan, responden diminta untuk memberikan tanda silang pada salah satu dari dua indikator yang dirasakan lebih dominan menimbulkan beban kerja mental terhadap pekerjaannya. Hasil dari kuesioner ini akan dihitung jumlah tally dari setiap indikator yang dirasakan paling berpengaruh.

Tabel 1. Hasil Kuesioner Indikator Pembobotan

\begin{tabular}{|c|c|c|c|c|c|c|c|c|}
\hline \multirow{2}{*}{ No } & \multirow{2}{*}{ Responden } & \multicolumn{6}{|c|}{ INDIKATOR } & \multirow{2}{*}{ TOTAL } \\
\hline & & $\mathbf{K M}$ & $\mathbf{K F}$ & KW & $\mathbf{P}$ & TU & TF & \\
\hline 1 & $\mathrm{~A}$ & 5 & 0 & 3 & 2 & 1 & 4 & 15 \\
\hline 2 & $\mathrm{~B}$ & 4 & 0 & 1 & 3 & 3 & 4 & 15 \\
\hline 3 & $\mathrm{C}$ & 5 & 0 & 2 & 3 & 1 & 4 & 15 \\
\hline 4 & $\mathrm{D}$ & 4 & 0 & 1 & 3 & 2 & 5 & 15 \\
\hline 5 & $E$ & 1 & 0 & 3 & 5 & 3 & 3 & 15 \\
\hline 6 & $\mathrm{~F}$ & 5 & 0 & 3 & 1 & 2 & 4 & 15 \\
\hline 7 & $\mathrm{G}$ & 2 & 1 & 5 & 2 & 2 & 3 & 15 \\
\hline 8 & $\mathrm{H}$ & 1 & 0 & 3 & 2 & 4 & 5 & 15 \\
\hline 9 & $\mathrm{I}$ & 3 & 2 & 1 & 5 & 4 & 0 & 15 \\
\hline 10 & $\mathrm{~J}$ & 4 & 0 & 1 & 3 & 2 & 5 & 15 \\
\hline
\end{tabular}




\begin{tabular}{|c|c|c|c|c|c|c|c|c|}
\hline \multirow{2}{*}{ No } & \multirow{2}{*}{ Responden } & \multicolumn{6}{|c|}{ INDIKATOR } & \multirow{2}{*}{ TOTAL } \\
\hline & & $\mathbf{K M}$ & KF & KW & $\mathbf{P}$ & $\mathbf{T U}$ & TF & \\
\hline 11 & $\mathrm{~K}$ & 4 & 0 & 2 & 1 & 3 & 5 & 15 \\
\hline 12 & $\mathrm{~L}$ & 4 & 1 & 4 & 0 & 2 & 4 & 15 \\
\hline 13 & $\mathrm{M}$ & 3 & 2 & 5 & 0 & 1 & 4 & 15 \\
\hline 14 & $\mathrm{~N}$ & 4 & 0 & 2 & 3 & 2 & 4 & 15 \\
\hline 15 & $\mathrm{O}$ & 5 & 4 & 2 & 1 & 3 & 0 & 15 \\
\hline 16 & $\mathrm{P}$ & 2 & 4 & 4 & 1 & 3 & 1 & 15 \\
\hline
\end{tabular}

Pemberian rating merupakan tahap selanjutnya setelah dilakukannya tahap pembobotan. Pada bagian ini responden diminta untuk memberikan rating dari skala 0 - 100 dari keenam indikator beban mental. Rating yang diberikan subyektif bergantung dari beban mental yang dirasakan oleh para responden.

Tabel 2. Hasil Kuesioner Pemberian Rating

\begin{tabular}{|c|c|c|c|c|c|c|c|}
\hline \multirow{2}{*}{ No } & \multirow{2}{*}{ Responden } & \multicolumn{7}{|c|}{ INDIKATOR } \\
\cline { 2 - 8 } & & KM & KF & KW & P & TU & TF \\
\hline 1 & A & 90 & 80 & 100 & 100 & 100 & 100 \\
\hline 2 & B & 100 & 50 & 90 & 100 & 90 & 100 \\
\hline 3 & C & 80 & 80 & 70 & 80 & 90 & 80 \\
\hline 4 & D & 90 & 50 & 90 & 100 & 100 & 100 \\
\hline 5 & E & 100 & 90 & 100 & 100 & 100 & 100 \\
\hline 6 & F & 90 & 70 & 90 & 80 & 80 & 70 \\
\hline 7 & G & 80 & 80 & 90 & 90 & 100 & 90 \\
\hline 8 & H & 80 & 50 & 100 & 80 & 80 & 90 \\
\hline 9 & I & 90 & 100 & 90 & 90 & 100 & 80 \\
\hline 10 & J & 90 & 50 & 90 & 100 & 100 & 100 \\
\hline 11 & K & 100 & 100 & 100 & 80 & 100 & 100 \\
\hline 12 & L & 80 & 80 & 90 & 80 & 80 & 70 \\
\hline 13 & M & 90 & 90 & 90 & 90 & 90 & 80 \\
\hline 14 & N & 90 & 80 & 90 & 90 & 90 & 80 \\
\hline 15 & O & 100 & 100 & 100 & 100 & 100 & 100 \\
\hline 16 & P & 60 & 70 & 60 & 60 & 70 & 70 \\
\hline
\end{tabular}

Tabel 3. Nilai WWL

\begin{tabular}{|c|c|c|c|c|c|c|c|}
\hline Responden & KM & KF & KW & $\mathbf{P}$ & TU & TF & $\mathbf{W W L}$ \\
\hline A & 450 & 0 & 300 & 200 & 100 & 400 & 1450 \\
\hline B & 400 & 0 & 90 & 300 & 270 & 400 & 1460 \\
\hline C & 400 & 0 & 140 & 240 & 90 & 320 & 1190 \\
\hline D & 360 & 0 & 90 & 300 & 200 & 500 & 1450 \\
\hline E & 100 & 0 & 300 & 500 & 300 & 300 & 1500 \\
\hline F & 450 & 0 & 270 & 80 & 160 & 280 & 1240 \\
\hline
\end{tabular}




\begin{tabular}{|c|c|c|c|c|c|c|c|}
\hline Responden & KM & KF & KW & $\mathbf{P}$ & TU & TF & $\boldsymbol{\Sigma} W W L$ \\
\hline G & 160 & 80 & 450 & 180 & 200 & 270 & 1340 \\
\hline H & 80 & 0 & 300 & 160 & 320 & 450 & 1310 \\
\hline I & 270 & 200 & 90 & 450 & 400 & 0 & 1410 \\
\hline J & 360 & 0 & 90 & 300 & 200 & 500 & 1450 \\
\hline K & 400 & 0 & 200 & 80 & 300 & 500 & 1480 \\
\hline L & 320 & 80 & 360 & 0 & 160 & 280 & 1200 \\
\hline M & 270 & 180 & 450 & 0 & 90 & 320 & 1310 \\
\hline N & 360 & 0 & 180 & 270 & 180 & 320 & 1310 \\
\hline O & 500 & 400 & 200 & 100 & 300 & 0 & 1500 \\
\hline P & 120 & 280 & 240 & 60 & 210 & 70 & 980 \\
\hline
\end{tabular}

Berdasarkan teori interprestasi skor NASA-TLX, maka didapatkan hasil rekapitulasi perhitungan nilai WWL dan golongan beban kerja yang di rasakan responden/personel ATC seperti yang terlihat pada tabel 4 .

Tabel 4. Rekapitulasi Perhitungan Nilai WWL

\begin{tabular}{|c|c|c|c|c|c|c|c|c|c|}
\hline Responden & $\mathbf{K M}$ & $\mathbf{K F}$ & $\mathbf{K W}$ & $\mathbf{P}$ & $\mathbf{T U}$ & $\mathbf{T F}$ & $\mathbf{J m l}$ & $\begin{array}{c}\text { Rata-rata } \\
\text { (skor) }\end{array}$ & $\begin{array}{c}\text { Golongan } \\
\text { Beban Kerja }\end{array}$ \\
\hline $\mathbf{A}$ & 450 & 0 & 300 & 200 & 100 & 400 & 1450 & $\mathbf{9 7}$ & $\begin{array}{c}\text { SANGAT } \\
\text { TINGGI }\end{array}$ \\
\hline $\mathbf{B}$ & 400 & 0 & 90 & 300 & 270 & 400 & 1460 & $\mathbf{9 7}$ & $\begin{array}{c}\text { SANGAT } \\
\text { TINGGI }\end{array}$ \\
\hline $\mathbf{C}$ & 400 & 0 & 140 & 240 & 90 & 320 & 1190 & $\mathbf{7 9}$ & TINGGI \\
\hline $\mathbf{D}$ & 360 & 0 & 90 & 300 & 200 & 500 & 1450 & $\mathbf{9 7}$ & $\begin{array}{c}\text { SANGAT } \\
\text { TINGGI }\end{array}$ \\
\hline $\mathbf{E}$ & 100 & 0 & 300 & 500 & 300 & 300 & 1500 & $\mathbf{1 0 0}$ & $\begin{array}{c}\text { SANGAT } \\
\text { TINGGI }\end{array}$ \\
\hline $\mathbf{F}$ & 450 & 0 & 270 & 80 & 160 & 280 & 1240 & $\mathbf{8 3}$ & $\begin{array}{c}\text { SANGAT } \\
\text { TINGGI }\end{array}$ \\
\hline $\mathbf{G}$ & 160 & 80 & 450 & 180 & 200 & 270 & 1340 & $\mathbf{8 9}$ & $\begin{array}{c}\text { SANGAT } \\
\text { TINGGI }\end{array}$ \\
\hline $\mathbf{H}$ & 80 & 0 & 300 & 160 & 320 & 450 & 1310 & $\mathbf{8 7}$ & $\begin{array}{c}\text { SANGAT } \\
\text { TINGGI }\end{array}$ \\
\hline $\mathbf{I}$ & 270 & 200 & 90 & 450 & 400 & 0 & 1410 & $\mathbf{9 4}$ & $\begin{array}{c}\text { SANGAT } \\
\text { TINGGI }\end{array}$ \\
\hline $\mathbf{J}$ & 360 & 0 & 90 & 300 & 200 & 500 & 1450 & $\mathbf{9 7}$ & $\begin{array}{c}\text { SANGAT } \\
\text { TINGGI }\end{array}$ \\
\hline $\mathbf{K}$ & 400 & 0 & 200 & 80 & 300 & 500 & 1480 & $\mathbf{9 9}$ & $\begin{array}{c}\text { SANGAT } \\
\text { TINGGI }\end{array}$ \\
\hline 320 & 80 & 360 & 0 & 160 & 280 & 1200 & $\mathbf{8 0}$ & $\begin{array}{c}\text { SANGAT } \\
\text { TINGGI }\end{array}$ \\
\hline
\end{tabular}




\begin{tabular}{|c|c|c|c|c|c|c|c|c|c|}
\hline Responden & $\mathbf{K M}$ & $\mathbf{K F}$ & $\mathbf{K W}$ & $\mathbf{P}$ & $\mathbf{T U}$ & $\mathbf{T F}$ & $\mathbf{J m l}$ & $\begin{array}{c}\text { Rata-rata } \\
\text { (skor) }\end{array}$ & $\begin{array}{c}\text { Golongan } \\
\text { Beban Kerja }\end{array}$ \\
\hline $\mathbf{M}$ & 270 & 180 & 450 & 0 & 90 & 320 & 1310 & $\mathbf{8 7}$ & $\begin{array}{c}\text { SANGAT } \\
\text { TINGGI }\end{array}$ \\
\hline $\mathbf{N}$ & 360 & 0 & 180 & 270 & 180 & 320 & 1310 & $\mathbf{8 7}$ & $\begin{array}{c}\text { SANGAT } \\
\text { TINGGI }\end{array}$ \\
\hline $\mathbf{O}$ & 500 & 400 & 200 & 100 & 300 & 0 & 1500 & $\mathbf{1 0 0}$ & $\begin{array}{c}\text { SANGAT } \\
\text { TINGGI }\end{array}$ \\
\hline $\mathbf{P}$ & 120 & 280 & 240 & 60 & 210 & 70 & 980 & $\mathbf{6 5}$ & SEDANG \\
\hline Total & $\mathbf{5 0 0 0}$ & $\mathbf{1 2 2 0}$ & $\mathbf{3 7 5 0}$ & $\mathbf{3 2 2 0}$ & $\mathbf{3 4 8 0}$ & $\mathbf{4 9 1 0}$ & $\mathbf{2 1 5 8 0}$ & $\mathbf{1 4 3 9}$ & \\
\hline Rata-rata & $\mathbf{3 1 3}$ & $\mathbf{7 6}$ & $\mathbf{2 3 4}$ & $\mathbf{2 0 1}$ & $\mathbf{2 1 8}$ & $\mathbf{3 0 7}$ & $\mathbf{1 3 4 9}$ & $\mathbf{9 0}$ & $\begin{array}{c}\text { SANGAT } \\
\text { TINGGI }\end{array}$ \\
\hline
\end{tabular}

Berdasarkan hasil dari rekapitulasi perhitungan nilai rata-rata WWL pada setiap personel ATC di AirNav Indonesia Kantor Cabang Bandar Udara Adisutjipto dengan menggunakan metode NASA-TLX, maka didapatkan hasil beban kerja mental personel ATC berada pada tingkat TINGGI sebanyak 2 orang dan pada tingkat SANGAT TINGGI sebanyak 14 orang dengan keterangan sebagai berikut:

- Responden A

Beban kerja mental pada responden 1 sebesar 97 dan berdasarkan interprestasi nilai skor menurut Simanjuntak dan Situmorang (2010) maka termasuk kedalam kategori beban kerja mental SANGAT TINGGI.

- Responden B

Beban kerja mental pada responden B sebesar 97 dan berdasarkan interprestasi nilai skor menurut Simanjuntak dan Situmorang (2010) maka termasuk kedalam kategori beban kerja mental SANGAT TINGGI.

- Responden C

Beban kerja mental pada responden $\mathrm{C}$ sebesar 79 dan berdasarkan interprestasi nilai skor menurut Simanjuntak dan Situmorang (2010) maka termasuk kedalam kategori beban kerja mental TINGGI.

- Responden D

Beban kerja mental pada responden D sebesar 97 dan berdasarkan interprestasi nilai skor menurut Simanjuntak dan Situmorang (2010) maka termasuk kedalam kategori beban kerja mental SANGAT TINGGI.

- Responden E

Beban kerja mental pada responden E sebesar 100 dan berdasarkan interprestasi nilai skor menurut Simanjuntak dan Situmorang (2010) maka termasuk kedalam kategori beban kerja mental SANGAT TINGGI.

- Responden F

Beban kerja mental pada responden $\mathrm{F}$ sebesar 83 dan berdasarkan interprestasi nilai skor menurut Simanjuntak dan Situmorang (2010) maka termasuk kedalam kategori beban kerja mental SANGAT TINGGI.

- Responden G

Beban kerja mental pada responden G sebesar 89 dan berdasarkan interprestasi nilai skor menurut Simanjuntak dan Situmorang (2010) maka termasuk kedalam kategori beban kerja mental SANGAT TINGGI. 
- Responden $\mathrm{H}$

Beban kerja mental pada responden $\mathrm{H}$ sebesar 87 dan berdasarkan interprestasi nilai skor menurut Simanjuntak dan Situmorang (2010) maka termasuk kedalam kategori beban kerja mental SANGAT TINGGI.

- Responden I

Beban kerja mental pada responden I sebesar 94 dan berdasarkan interprestasi nilai skor menurut Simanjuntak dan Situmorang (2010) maka termasuk kedalam kategori beban kerja mental SANGAT TINGGI.

- Responden J

Beban kerja mental pada responden J sebesar 97 dan berdasarkan interprestasi nilai skor menurut Simanjuntak dan Situmorang (2010) maka termasuk kedalam kategori beban kerja mental SANGAT TINGGI.

- Responden K

Beban kerja mental pada responden K sebesar 99 dan berdasarkan interprestasi nilai skor menurut Simanjuntak dan Situmorang (2010) maka termasuk kedalam kategori beban kerja mental SANGAT TINGGI.

- Responden L

Beban kerja mental pada responden L sebesar 80 dan berdasarkan interprestasi nilai skor menurut Simanjuntak dan Situmorang (2010) maka termasuk kedalam kategori beban kerja mental SANGAT TINGGI.

- Responden M

Beban kerja mental pada responden 1 sebesar 87 dan berdasarkan interprestasi nilai skor menurut Simanjuntak dan Situmorang (2010) maka termasuk kedalam kategori beban kerja mental SANGAT TINGGI.

- Responden N

Beban kerja mental pada responden $\mathrm{N}$ sebesar 87 dan berdasarkan interprestasi nilai skor menurut Simanjuntak dan Situmorang (2010) maka termasuk kedalam kategori beban kerja mental SANGAT TINGGI.

- Responden O

Beban kerja mental pada responden O sebesar 100 dan berdasarkan interprestasi nilai skor menurut Simanjuntak dan Situmorang (2010) maka termasuk kedalam kategori beban kerja mental SANGAT TINGGI.

- Responden P

Beban kerja mental pada responden $\mathrm{P}$ sebesar 65 dan berdasarkan interprestasi nilai skor menurut Simanjuntak dan Situmorang (2010) maka termasuk kedalam kategori beban kerja mental TINGGI.

Berdasarkan beban kerja mental dari 16 (enam belas) responden, maka diperoleh nilai rata-rata WWL beban kerja mental responden sebesar 90 dan berdasarkan interprestasi nilai skor menurut Simanjuntak dan Situmorang (2010) maka termasuk kedalam kategori beban kerja mental SANGAT TINGGI.

Dari enam indikator yang ada jumlah keseluruhan yang tertinggi terdapat pada indikator kebutuhan mental, personel ATC di AirNav Indonesia Kantor Cabang Bandar Udara Adisutjipto dapat disimpulkan bahwa dari keseluruhan personel ATC mengalami kebutuhan mental yang sangat tinggi dikarenakan dalam bekerja personel ATC dituntut untuk berkonsentasi tinggi dalam memantau navigasi, radiasi serta mengawasi dan melaksanakan pemanduan pesawat dengan tujuan untuk menjamin keamanan serta keteraturan traffic dalam pelayanan lalu lintas penerbangan. Salah satunya dimungkinkan karena kepadatan jumlah frekuensi penerbangan dan kompleksitas pelayanan penerbangan di bandar udara Internasional Yogyakarta. 
Dari enam indikator beban kerja mental, total keseluruhan nilai product terendah terdapat pada indikator kebutuhan fisik, hal itu dimungkinkan karena personel ATC bekerja lebih mengedepankan otak disbanding fisik. Kebutuhan fisik merupakan faktor penunjang terlaksananya aktivitas kerja para air traffic controller secara optimal. aktivitas yang mereka lakukan dengan mata, telinga, tangan dan mulut merupakan aktivitas dalam keseharian tugas kerja mengingat dalam melakukan pemanduan lalu lintas udara memerlukan aktifitas fisik, seperti berkomunikasi dengan pilot sambil menulis di flight strip, melihat terus menerus layar monitor tanpa jeda, berkoordinasi dengan ATC unit, berbicara dengan lantang dan jelas kepada pilot.Dari enam indikator beban kerja mental, indikator tekanan waktu memiliki total nilai product tertinggi ketiga, semakin tinggi tingkat kepadatan penerbangan dan kompleksitas pelayanan lalu lintas penerbangan, semakin tinggi tekanan waktu yang dirasakan oleh para controller.Dari enam indikator beban kerja mental, indikator performance yang dicapai para air traffic controller di bandar udara internasional Yogyakarta memiliki nilai product terendah kedua setelah indikator kebutuhan fisik, dimungkinkan adanya pengaruh tingkat kompleksitas pelayanan penerbangan terhadap performance pada kepuasan kerja dan hasil kerja para controller. Semakin tinggi tingkat kompleksitas pelayanan penerbangan semakin tinggi tingkat performance para air traffic controller. Keadaan ini terjadi karena peralatan yang lebih lengkap dengan tingkat teknologi yang lebih tinggi, ditambah dengan pelatihan kerja para controller yang lebih baik. Dari enam indikator beban kerja mental, indikator tingkat usaha memiliki total nilai product tertinggi ke empat atau terendah ke tiga, semakin tinggi tingkat kepadatan penerbangan dan tingkat pelayanan penerbangan sebuah bandara, maka akan semakin tinggi juga tingkat usaha (efforts). Dari enam indikator beban kerja mental, indikator tingkat frustasi memiliki total nilai product tertinggi kedua, tingkat frustasi atau Frustation Level dapat dianologikan sebagai stress kerja, dimungkinkan karena tidak bisa dipungkiri air traffic controller dalam bekerja akan menghadapi masalah, deteksi/resolusi konflik.

\section{Beberapa Upaya Untuk Mengurangi Beban Kerja}

- Untuk menjaga beban kerja ATC berada dalam kategori medium load perlu dilakukan penambahan sektorisasi. Dengan membagi sektor TMA menjadi 2 wilayah yaitu TMA East dan TMA West dengan asumsi kondisi pada kedua sektor tersebut sama, dengan demikian maka kan mngurangi presentase beban kerja sebanyak $45 \%$

- Regulator maupun pemegang kebijakan terhadap ATC perlu memperhatikan jam kerja, istirahat dan jumlah personel ATC yang bertugas. Hal ini menjadi penting karena pengelolaan kerja yang baik dapat meminimalisir tingkat kelelahan dan stres kerja dari ATC.

- Lingkungan Kerja dan hubungan kerja antar ATC dan hubungan antar ATC dengan supervisor juga perlu dibina, agar tidak menambah beban kerja dan stres kerja ATC.

- Meningkatkan fasilitas yang ada di bandara, khususnya fasilitas bagi para air traffic controller agar dapat digunakan dalam menunjang pelayanan lalu lintas udara.

- Melakukan training bagi para controller untuk menambah ketrampilan atau skill dalam memandu lalu lintas udara. Hal ini diperlukan untuk menambah kemampuan dan meningkatkan mental para personil saat menghadapi masalah yang ada di bandara.

- Pengaturan jadwal dinas dan jadwal istirahat yang tepat, dengan menyesuaikan jumlah traffic yang ada di Yogyakarta. Hal ini bertujuan agar mencegah peningkatan tingkat stres kerja dan juga kelelahan akibat jumlah istirahat yang kurang bagi para controller.

$>$ Penambahan knowledge/pengetahuan seperti pembaharuan SOP karena pergerakan dari traffic semakin tahun akan bertambah, dan rutenya juga bisa jadi akan berubah demi efisiensi penerbangan. 


\section{Kesimpulan}

Tingkat beban kerja para air traffic controller di bandar udara Internasional Adisutjipto rata-rata berada pada tingkat sangat tinggi.Dari enam indikator beban kerja mental, jumlah dari product indikator kebutuhan mental mendapatkan hasil tertinggi dan indikator kebutuhan fisik mendapatkan hasil terendah, hal ini dimungkinkan karena dalam bekerja personel ATC lebih mengedepakan otak disbanding fisik, dan mengingat pekerjaan seorang air traffic controller memiliki kompleksitas kerja seperti mengingat, melihat, mencari dan interprestasi atas tugas pengontrolan pesawat.Dari hasil penyebaran kuesioner kepada personel ATC mengenai peningkatan peralatan navigasi dari konvensional menjadi performance Base Navigation (PBN) apakah dapat mengurangi beban kerja ATC dalam memandu lalu lintas udara dan dapat meningkatkan keselamatan lalu lintas udara. Didapatkan hasil 87.5\% personel ATC menjawab Ya/Setuju. Yang berarti bila bandar udara Internasional Adisutjipto melakukan peningkatan peralatan navigasi dari konvensional menjadi PBN dapat mengurangi beban kerja mental air traffic controller.

\section{DAFTAR PUSTAKA}

[1] Susanti. 2013. "Analisis Kebutuhan Personel Air Traffic Controller (ATC) di Pusat Pengendalian Lalu Lintas Penerbangan Makassar". Jurnal Peneliti Bidang Transportasi Udara-Badan Litbang Perhubungan, Vol 25. No 2.

[2] Peraturan Menteri Perhubungan Republik Indonesia Nomor PM 65 Tahun 2017 tentang Peraturan Keselamatan Penerbangan Sipil Bagian 170 Bab 1 Point 1.5 Halaman 13

[3] Peraturan Menteri Perhubungan Republik Indonesia Nomor PM 65 Tahun 2017 tentang Peraturan Keselamatan Penerbangan Sipil Bagian 170 Bab 1 Point 1.4 Halaman 13

[4] Haryono. 2004. "Beban Kerja". Physicology, diakses dari http://psychologynkartikas.blogspot.com/2016/09/beban-kerja.html diakses 2 Desember 2020 pukul 10.00

[5] Peraturan Menteri Perhubungan Republik Indonesia Nomor PM 65 Tahun 2017 tentang Peraturan Keselamatan Penerbangan Sipil Bagian 170 Bab 1 Point 1.4 Halaman 13 PM No 65 tahun 2017 tentang peraturan keselamatan penerbangan sipil (PKPS) bagian 170 Bab 1 Point 1.5 Halaman 13

[6] PM No 65 tahun 2017 tentang peraturan keselamatan penerbangan sipil (PKPS) bagian 170 Bab 1 Point 1.5 Hal 14

[7] PM No 65 tahun 2017 tentang Peraturan Keselamatan Penerbangan Sipil (PKPS) bagian 170 Bab 1 Point 1.9 Hal 19

[8] Direktur Jenderal Perhubungan Udara Nomor KP 287 tahun tentang pedoman teknis operasional bagian 69-01 (Advisory Circular part 69-01) Bab V Pasal 49 Hal 4. Human Factors Digest No.8

[9] Hancock, A. Peter and N. Meshkati (1998). Human Mental Workload Netherlands: Elsevier Science Publishing Company, INC

[10] Ardhia, Wartha. 2016. "Faktor Penyebab Kelelahan dan Stres Kerja Terhadap Personel Air Traffic Controller (ATC) di Bandar Udara "X"'. Jurnal Perhubungan Udara. Vol 42. No 3.

[11] Patra, Siti, Laila. 2018. "Pengaruh Beban Kerja Air Traffic Controller Terhadap Stres Kerja di Bandar Udara Internasional Juanda”. Jurnal Teknologi Penerbangan. Vol 2. No 2. 